\title{
CUANDO LAS AFRENTAS SE LAVABAN CON SANGRE: HONOR, MASCULINIDAD Y DUELOS DE ESPADAS EN EL SIGLO XVIII CHILENO ${ }^{2}$
}

\begin{abstract}
Este trabajo aborda la relación entre honor y prácticas sociales en el siglo XVIII chileno, analizando la figura de los duelos o expresiones de violencia masculina formalizada. Junto con indagar en los mecanismos restitutorios del honor y su vinculación a los fundamentos de una masculinidad tradicional, reflexiona sobre las gamas de manejo social de dicho valor en el período señalado. Teóricamente se rescatan los aportes de la antropología y se hace un balance del tratamiento historiográfico del problema. Desde los registros judiciales se plantea el carácter transversal del honor en términos sociales y se aborda su "doble naturaleza" en cuanto espacio relacional y ámbito de confrontación de los individuos.
\end{abstract}

Palabras clave: Honor, duelos, violencia, masculinidad, siglo XVIII chileno.

This works deals with the relationship between honor and social practices in Chile's eighteenth century and analyzes formal duels or expressions of legalized masculine violence. This article explores various manifestations of the social ways used to deal with honor at that time, together with the inquiries about mechanisms used to restore honor and its links with traditional masculinity. Theoretically, this work rescues contributions made by anthropologists and provides an overview of how honor and masculinity have been examined in the historiography. Starting from judicial records, the article considers the transversal character of honor in social terms and approaches its "double significance" as both a relational space for people and as a sphere for the confrontation of individuals.

Key words: Honor, Duels, Violence, Masculinity, Eighteenth Century Chile

Fecha de recepción: marzo 2007

Fecha de aceptación: noviembre 2007

1 Candidata a Doctora en Historia por la Pontificia Universidad Católica de Chile, Becaria CONICYT. Correo electrónico: vundurra@uc.cl

2 Este artículo es parte de la investigación elaborada en el marco de la tesis para obtener el grado de Doctor en Historia en la Pontificia Universidad Católica de Chile, En busca de honor: Identidades, representaciones y prácticas culturales de los grupos medios y populares en Santiago colonial (1700-18800) dirigido por el profesor Jaime Valenzuela Márquez y que ha contado con valioso aporte de CONICYT. Una versión preliminar, en forma de ponencia, fue presentada en el $V$ Encuentro de Historia Colonial, Universidad Andrés Bello, Santiago, octubre 2006. 


\section{INTRODUCCIÓN}

Una historia de los usos sociales del honor comporta necesariamente el análisis de los sistemas de valores socioculturales que todo grupo humano construye para evaluar, premiar o sancionar los patrones de acción y de posesión -material o simbólica- de sus integrantes. Ella, por tanto, nos relaciona con los referentes culturales de las sociedades del pasado, abriendo ventanas para la observación de representaciones y prácticas que adquirían significación para quienes compartían los mismos universos mentales ${ }^{3}$. En este último sentido, podemos decir que una de las facetas del honor ha consistido en construir nexos de comunicación que permiten el diálogo intercomunitario, conformando un lenguaje común que cruza transversalmente la sociedad ${ }^{4}$. Ahora bien, tales dinámicas no han impedido que, a su vez, el honor preste sus categorías para un juego de competencias que hayan quebrado los diálogos y fomentado las rivalidades individuales y colectivas respecto de sus usos y atributos. Es esta dualidad entre espacio relacional y ámbito de confrontación la que explica la complejidad del fenómeno y la que sustenta analíticamente esta presentación.

El honor, en tanto valor secular preferente de las sociedades tradicionales, ha sido objeto de permanentes luchas simbólicas desarrolladas dentro de la sociedad por ungir determinadas formas culturales como "legítimas"5. El control y selección de las múltiples prácticas y formas discursivas, llevado a cabo por el poder y el saber del momento histórico, terminarían consagrando el discurso de las élites como el discurso verdadero del honor ${ }^{6}$. Es justamente la instalación de este discur-

3 Respecto a ello, el antropólogo Peristiany, uno de los referentes en el estudio del honor en las sociedades mediterráneas, ha señalado que honor y deshonor, "son el reflejo de la personalidad social en el espejo de los ideales sociales". J. G. Peristiany (ed.), El concepto de honor en la sociedad mediterránea, Barcelona, Labor, 1968, 12. Por representación entendemos los sistemas de percepción y de juicio que los individuos singulares o las comunidades de interpretación significan y construyen del mundo social. Bajo el concepto de prácticas se hará referencia a las experiencias y maneras como las personas materializaban lo que para ellas significaba el honor. Roger Chartier, El mundo como representación. Estudios sobre historia cultural, Barcelona, Gedisa, 1992. Para algunas reflexiones críticas sobre la noción de representación, véase Carlo Ginzburg, Ojazos de madera. Nueve reflexiones sobre la distancia, Barcelona, Península, 2000, 85-88.

4 Sobre el carácter transversal y polisémico del honor colonial chileno véase Verónica Undurraga, "Honores transversales, honores polisémicos en la sociedad chilena del siglo XVIII", en A. Araya, A. Candina y C. Cussen (eds.), Del nuevo al viejo mundo: mentalidades y representaciones desde América, Santiago, Fondo de Publicaciones Americanistas y Facultad de Humanidades de la Universidad de Chile, 2008, 53-65.

5 Por "luchas simbólicas" entendemos, siguiendo a Pierre Bourdieu, las disputas por la apropiación de los signos distintivos que fundan el capital cultural de una sociedad. Se trata de "luchas en las que lo que se encuentra en juego es todo lo que, en el mundo social, es del orden de la creencia, del crédito o del descrédito, de la percepción y de la apreciación, del conocimiento y del reconocimiento, nombre, renombre, prestigio, honor, gloria, autoridad, todo lo que constituye el poder simbólico como poder reconocido". Pierre Bourdieu, La distinción. Criterio y bases sociales del gusto, Madrid, Taurus, 2000, 248.

6 Por élite hacemos referencia a un conjunto selecto y reducido de personas que gozaban de prerrogativas sociales, económicas y políticas en un determinado contexto social, económico y político. Véase Jacques A. Barbier, "Elite and Cadres in Bourbon Chile", Hispanic American Historical Review (en adelante $H A H R$ ), 52 (3), 1972, 416-435. Tomamos la noción de discurso propuesta por Foucault, como sistema de posibilidad de conocimiento. En cuanto tal, no se trataría solo de una forma 
so verdadero del honor como referente cultural, la que nos permite explicar el silencio -o más bien la ocultación- de las otras formas discursivas existentes en el período y que se muestran, por ejemplo, entre las líneas de los registros judiciales ${ }^{7}$.

A esta discursividad elitista, se le sumaban una serie de valores, prácticas y normas que construían lo que podemos llamar la cultura del honor aristocrática, entendiendo esta última como un sistema de significaciones que dan sentido a un orden de comportamientos, mecanismos de juicio y de relación con determinados bienes económicos. Es así como los fundamentos materiales del poder se revestían de carga simbólica, pasando a ser significantes del prestigio, tal como ha sucedido con la catalogación de "nobles" de algunos tipos de bienes raíces, de ciertas actividades o de determinados cultivos agrícolas que eran justamente aquellos vinculados a las élites.

Ahora bien, tras la fachada de una cultura legítima del honor, que definía modos idóneos de utilización y comprensión, existían códigos alternativos y transversales que cruzaban todo el cuerpo social. La unicidad y exclusividad del honor, propuestas por su discurso verdadero, eran solo ilusorias y respondían más a la voluntad de orden de unos pocos que a las dinámicas de una realidad social compleja como la del siglo XVIII chileno. Ello no solo nos habla, siguiendo a Frédérique Langue, de "la polisemia de los universos normativos y de las estructuras mentales" 8 de las sociedades coloniales americanas, sino que asimismo de la actualización, resignificación y manipulación de las representaciones y prácticas del honor por gran parte de los actores sociales del período ${ }^{9}$. Se trataba de un manejo

de expresión, sino que de la disposición que conforma las experiencias y los conocimientos. Michel Foucault, El orden del discurso, Barcelona, Tusquets, 2002; Michel Foucault, Arqueología del saber, Buenos Aires, Siglo XXI, 2003.

7 Es importante tener en cuenta la mediación, a veces altamente deformadora, de fuentes producidas por los grupos dominantes. Ella plantea la discusión sobre las dificultades metodológicas para acceder tanto a los discursos y prácticas no oficiales, como a las ideas, percepciones y sistemas valóricos de los grupos populares. Si bien los archivos judiciales insertan su contenido dentro de las estructuras de poder propias de cada momento histórico, reflejando los modelos culturales de quienes las sostenían, dejan algunos espacios para que los individuos del bajo pueblo y de los grupos medios expresen sus imágenes de mundo. Pese a que dentro de las instancias judiciales, estos sujetos tenían en mente las reglas y expectativas de las autoridades, sus testimonios iniciales no solían caer en formulismos legales, lo que contrasta con las etapas medias y finales de los procesos, en las que la mediación institucional y la estilización se espesan notablemente.

$8 \quad$ Frédérique Langue, "Les identités fractales: honneur et couleur dans la société vénézuélienne du XVIIIe siècle", Caravelle, $\mathrm{N}^{\circ}$ 65, 1995, 25 (la traducción es nuestra).

9 El manejo social de las identidades ha sido referido especialmente a aquellas derivadas del origen/color de los actores coloniales. Berta Ares Queija, "Mestizos en hábito de indios: ¿estrategias transgresoras o identidades difusas?", en R. M. Loureiro y Serge Gruzinski (eds.), Passar as fronteiras. Il coloquio internacional sobre mediadores culturais, séculos XV a XVIII, Lagos, Centro de Estudios Gil Eanes, 1999, 133-146; Bernard Lavallé, Amor y opresión en los Andes centrales, Lima, IEP / IFEA / URP, 85-136. Al plantear la existencia de un manejo social del honor en el Chile del siglo XVIII, no solo postulamos la posibilidad de negociación de las identidades étnicas sino de todas aquellas vinculadas a las diversas facetas del honor, particularmente dentro de los grupos medios y populares. La sinonimia entre honor y buena conducta, o entre honor y virilidad, fueron algunos de los mecanismos utilizados por españoles pobres, indígenas y castas para construir representaciones alternativas de honor. Con ello, se soslayaba o al menos se minimizaba la importancia de criterios tradicionales, tales como el linaje. Véase Verónica Undurraga, "El honor no es más que la buena opinión: aproximación al honor a partir de la categoría de lo público en el Chile de 1792 a 1822", Bicentenario. Revista de Historia de Chile y América, Vol. 4, N 2, 2005, Santiago, 17-35. 
social del honor practicado cotidianamente y configurado desde las circunstancias étnicas, laborales y de género que sostenían las identidades y construían las alteridades dentro del mundo colonial chileno. Al ejercerlo, castas, españoles pobres, artesanos o peones daban cuenta de su capacidad operativa para moverse dentro de espacios jerárquicos, detectando y manejando los intersticios que las estructuras de dominación colonial no lograban sellar ${ }^{10}$. Esta perspectiva no pretende minimizar la acción de dispositivos de sujeción sobre parte importante de la población americana $^{11}$. Más bien refrenda su existencia, optando por miradas complementarias que permitan comprender las formas en que los sujetos coloniales resistieron, se acomodaron, manipularon y, en una palabra, vivieron bajo tales lineamientos ${ }^{12}$.

\section{PRESENCIAS Y AUSENCIAS DEL HONOR EN LA HISTORIOGRAFÍA CHILENA}

Si bien la pluralidad de códigos de honor para la América colonial es un fenómeno conocido y estudiado por la historiografía a lo largo de los últimos quince años, su análisis para el ámbito de la Capitanía General de Chile no ha recibido la misma atención de los investigadores ${ }^{13}$. Centrados en los ya mencionados "discursos verdaderos del honor", la producción historiográfica chilena generalmente ha

10 El término español se emplea aquí según el uso común de la época en estudio, es decir, haciendo referencia a aquellos individuos venidos de España, a los que descendían de hispanos e incluso a aquellos que, en razón de su fenotipo, pasaban por tales. Uniendo dicha noción al apelativo "pobre", como frecuentemente se encuentra en la documentación del período, se incorpora el criterio material para caracterizar más específicamente el lugar social de algunos "españoles” en la colonia.

11 La concepción de la sociedad colonial americana como una sociedad de dominación, con toda la gama de matices que esta noción puede tener, ha sido trabajada por diversos autores. Para el ámbito chileno podemos mencionar, entre otros, los trabajos de Sergio Villalobos, Historia del pueblo chileno, Tomo IV, Santiago, Editorial Universitaria, 1999, 211-294. Desde el punto de vista del disciplinamiento social, Leonardo León ha mostrado los mecanismos de control de la población desplegados por la élite ilustrada. Véanse sus trabajos, "Elite y bajo pueblo durante el período colonial. La guerra contra las pulperas en Santiago de Chile", Monografías de Cuadernos de Historia $N^{\circ} 1$, Historia de las mentalidades. Homenaje a Georges Duby, Santiago, Departamento de Ciencias Históricas, Universidad de Chile, 2000, 93-114; "La construcción del orden social oligárquico en Chile colonial: la creación del Cuerpo de Dragones, 1758", Estudios Coloniales I, Santiago, Universidad Andrés Bello, 2000, 183-195; "Reglamentando la vida cotidiana en Chile colonial, 1760-1768", Valles. Revista de estudios regionales, La Ligua, Año 4, No 4, 1998, 47-75.

12 Las estrategias de acomodación y manipulación del mundo social dan cuenta de la operatividad de una "racionalidad específica" en las acciones de los actores coloniales. El término "racionalidad específica" lo hemos tomado de Giovanni Levi, quien lo aplica al mundo campesino europeo del Antiguo Régimen. Giovanni Levi, La herencia inmaterial. La historia de un exorcista piamontés del siglo XVII, Madrid, Nerea, 1990, 11 y 12.

13 Lyman L. Johnson y Sonya Lipsett-Rivera, The faces of honor in Colonial Latin America. Sex, shame and violence, Albuquerque, University of New Mexico Press, 1998; María Eugenia Chaves, Honor y libertad. Discursos y recursos en la estrategia de libertad de una mujer esclava (Guayaquil a fines del período colonial), Goteborg, Departamento de Historia/Instituto Iberoamericano de la Universidad de Goteborg, 2001; Sarah Chambers, From Subjects to Citizens. Honor, Gender and Politics in Arequipa, Peru, 1780-1854, University Park PA, Pennsylvania State University Press, 1999; Frédérique Langue, "Les identités fractales", op. cit., 23-37; Frédérique Langue, Aristócratas, honor y subversión en la Venezuela del siglo XVIII, Caracas, Biblioteca de la Academia Nacional de la Historia, Serie Fuentes para la Historia de Venezuela, Vol. 252, 2000 
concebido este valor como atributo exclusivo de los grupos superiores de la sociedad. Si atendemos a las obras clásicas de Diego Barros Arana, Benjamín Vicuña Mackenna o Domingo Amunátegui Solar, por mencionar solo a algunos, constataremos que las observaciones más cercanas al respecto se refirieren al "espíritu aristocrático" de los criollos, que los llevaba a inclinarse "a los honores y distinciones de cualquier género"14. Una que otra alusión a los conflictos por el orden de precedencia en los actos oficiales, a las ejecutorias de hidalguía o a las profesiones de caballero en alguna orden militar, expresan en estas obras la adscripción distintiva de las prácticas del honor a la élite. Los trabajos genealógicos que sellan las preocupaciones identitarias de los grupos dominantes en torno al linaje, deteniéndose en los fundamentos materiales o simbólicos que les permitían acceder, reservar o incrementar el honor individual y colectivo a través de mayorazgos o títulos de Castilla, no hacen más que reproducir esta perspectiva ${ }^{15}$. Los hispanistas, en tanto, en su momento asociaron el concepto de honor a los hidalgos, aquellos fijos de bien, convertidos en arquetipos idealizados que cristalizaban la autopercepción de nobleza moral de una élite que remitía los vicios a las fronteras de su grupo ${ }^{16}$.

Las generaciones posteriores, bajo el influjo de corrientes historiográficas europeas como la historia de las mentalidades o el estructuralismo, encaminaron sus intereses a áreas soslayadas por otros investigadores, reflexionando sobre códigos de conducta y atributos valóricos que informaban la realidad cultural del pasado colonial. Así es como en las obras de Góngora hallamos alusiones a los basamentos de un esquivo y disputado prestigio social, al que no solo aspiraban sujetos enriquecidos en el comercio, sino asimismo individuos situados en los márgenes del cuerpo social, aquellos a quienes supuestamente les estaba vedado cualquier signo de estatus, obligados a vivir anónimamente dentro del grupo aparentemente homogéneo y generalizadamente "vicioso" de las $\operatorname{castas}^{17}$. El que individuos aleja-

14 Diego Barros Arana, Historia general de Chile, tomo VII, Santiago, Universitaria-DIBAM, 2000, 308. La descripción de los mestizos como sujetos viciosos y proclives a la bebida y al juego, ciertamente no contribuía a buscar fundamentos de honor dentro de los grupos medios o populares. Benjamín Vicuña Mackenna, Historia crítica y social de Santiago. 1541-1868, Santiago, Nascimento, 1924, Tomo II, 144 y 532.

15 Domingo Amunátegui Solar, Mayorazgos y títulos de Castilla, 3 vols., Santiago, Imprenta, Litografía I Encuadernación Barcelona, 1901; Juan Mujica, Linajes españoles. Nobleza colonial de Chile, 2 vols., Santiago, Zamorano y Caperán, 1927; Luis Thayer Ojeda, Familias chilenas, Santiago, Guillermo Miranda Editor, 1905; Juan Luis Espejo, Nobiliario de la Capitanía General de Chile, Santiago, Andrés Bello, 1967; Julio Retamal Favereau y otros, Familias fundadoras de Chile, 3 vols., Santiago, Universidad Católica de Chile, 1992, 2000, 2003. Asimismo, los diversos artículos de Luis Lira Montt refrendan la concepción del honor como un principio asociado a las élites. Su interés por el estudio de la nobleza en Indias, como institución social regulada por la Corona española, ha sido realizado desde el punto de vista histórico-jurídico e institucional. Algunos de sus trabajos son: "Beneméritos del Reino de Chile repertorio del siglo XVII", Boletín de la Academia Chilena de la Historia (en adelante $B A C h H), \mathrm{N}^{\circ} 105,1995,51-74$; "El fuero nobiliario en Indias", $B A C h H, \mathrm{~N}^{\circ} 89,1975$ 1976, 45-78; "La fundación de mayorazgos en Indias", $B A C h H, \mathrm{~N}^{\circ} 102,1991-1992,349-386$.

16 Jaime Eyzaguirre, Fisonomía histórica de Chile, Santiago, Ed. del Pacífico, 1958, 15-17, 21-23.

17 Sobre las preocupaciones en torno al prestigio social de parte de los comerciantes enriquecidos, véase Mario Góngora, Encomenderos y estancieros. Estudios acerca de la constitución social aristocrática de Chile después de la Conquista 1580-1660, Santiago, Universitaria, 1970, 80-87. El mismo autor, en su análisis de la estratificación social urbana en Chile colonial, hizo referencia a las expectativas de honor que tenían los pardos y a sus esfuerzos por desplegarlo a través de las gradacio- 
dos de los círculos de las élites hiciesen suyas reivindicaciones al honor obedecía, según Villalobos, a que "la cultura popular no podía escapar al ambiente dominante" de una "cultura hispanocriolla" preocupada especialmente por la honra ${ }^{18}$. Pese a que el "segmento de los dominados" conformó un espacio propio de formas de vida con el fin de contrarrestar la cultura oficial, formar parte del régimen y participar de sus beneficios habría sido el norte de muchos indígenas o mestizos pobres ${ }^{19}$. De este modo, el honor era circunscrito a un código unitario formulado por los grupos dominantes, donde cualquier pretensión a este equivalía a una inserción en el universo valórico de las élites.

Desde nuestra perspectiva, observamos que pese a que en diversas ocasiones las pretensiones de honor de castas y españoles pobres los obligaban a someterse a las visiones de mundo y a los parámetros de conducta de los grupos superiores, en otras instancias estos sujetos construían representaciones y validaban prácticas útiles a su lugar social, que entraban en disputa con las representaciones del honor de la élite ${ }^{20}$. El manejo social del honor se insertaba en la realidad cotidiana de hombres y mujeres que acudían a sus parámetros para ganar ventajas en las jerarquías de estimación y poder que existían dentro de sus propias comunidades, las que no estaban necesariamente al servicio de los intereses de la élite. Es por ello que una lectura del honor en clave hispánica, como atributo de los grupos dominantes y herramienta de control social, continúa reproduciendo las estructuras mentales y los parámetros conductuales de la élite, soslayando la existencia de manifestaciones alternativas de honor que respondan a las dinámicas particulares de todos los grupos de la sociedad colonial ${ }^{21}$. El acceso a estas últimas es posible a

nes militares en el siglo XVIII. Si bien, estas ideas no recibieron desarrollo sistemático en sus escritos, constituyeron miradas refrescantes que obligaron a centrar la atención en facetas que aportaban colorido y movilidad a la aparentemente quieta y gris siesta colonial. Mario Góngora, "Urban social stratification in colonial Chile", $H A H R, 55$ (3), august 1975, 440. Sobre el prestigio que los escalafones de las milicias urbanas otorgaban a las castas en el siglo XVIII chileno, véase Hugo Contreras, "Las milicias de pardos y morenos libres de Santiago de Chile en el siglo XVIII, 1760-1800", Cuadernos de Historia, $\mathrm{N}^{\mathrm{o}}$ 25, Santiago, 2006, 93-117.

18 Sergio Villalobos, op. cit., 284.

19 Ibid., 294.

20 Sobre las luchas entre representaciones discordantes del honor, véase Verónica Undurraga, "Honores transversales, honores polisémicos", op. cit.

21 En el marco de Chile colonial, la existencia de códigos de honor diversos a los sustentados por la élite, ha pasado desapercibida para la historiografía hasta hace solo pocos años, sin encontrar aún un estudio sistemático que, dialogando con diversos registros documentales, de cuenta de la diversidad de sus representaciones y prácticas, cuestión que actualmente estamos trabajando en el marco de nuestra tesis doctoral. Hasta el momento, los únicos trabajos destinados exclusivamente a analizar el honor en la sociedad chilena colonial, descontando aquellos de nuestra autoría ya mencionados en estas páginas, han sido "El concepto de honor en Chile colonial" y "Mujeres de Chillán luchan por su honra", ambos de Julio Retamal Ávila. En el primero, el análisis se centra en los fundamentos de poder y prestigio social de los grupos aristocráticos de los siglos XVI y XVII, consignando para el siglo XVIII un cambio en el "concepto de honor" derivado de la penetración de "gente nueva" en los núcleos de la élite. Asimismo, el autor acepta la posibilidad que dicha noción "traspasara" a los integrantes del "emergente grupo medio" e incluso a algunos indígenas, particularmente a los caciques. En el segundo artículo, se introduce la importancia de la pureza sexual femenina en la conformación del honor hispanocriollo. Véase Julio Retamal Ávila, "El concepto de honor en Chile colonial", Estudios Coloniales II, Universidad Andrés Bello, Santiago, 2002, 41-56; "Mujeres de Chillán luchan por su honra", Estudios Coloniales III, Universidad Andrés Bello, Santiago, 2004, 113-127. La última temática ha 
través de una historiografía que se preocupe más por los usos sociales efectivos que por los lineamientos generales que prescribían modelos conductuales no siempre seguidos ${ }^{22}$. De este modo, el análisis de las prácticas del honor en el Chile del siglo XVIII nos permitirá conocer las formas en que estas dialogaban con normativas y costumbres, generando un espacio creativo de nuevos usos y representaciones, en una dinámica que hemos denominado manejo social del honor.

La factibilidad de este ámbito de interacción se daba en la medida en que actores de los más diversos lugares sociales participasen de él, lo que nos relaciona con algunas de las últimas discusiones historiográficas sobre el honor. Ya es un lugar común dentro del análisis de esta temática en América colonial sostener que individuos de todos los espacios sociales estaban familiarizados o invocaban para sí tal o cual gesto o tratamiento de honor ${ }^{23}$. Sin embargo, para un espacio histórico cuyas altas esferas de poder imponían restricciones legales, sociales y de origen/ color a los anhelos de honor, las preguntas que podamos plantear acerca de los actores que buscaron, encontraron y ostentaron este ideal deben tener en cuenta dinámicas sociales más amplias, tales como los mecanismos de circulación cultural o la construcción de identidades individuales y colectivas.

$\mathrm{Si}$, por ejemplo, entendemos las reivindicaciones de honor realizadas ante la justicia por peones o artesanos como estrategias discursivas que buscaban el favor

sido una variable privilegiada, que ha tendido a monopolizar la historiografía del honor en América colonial. Los aportes de la historia de género han sido vitales en estas preocupaciones, abordando temáticas como la sexualidad, el matrimonio, la familia y la mujer. Dentro de estos análisis se cuentan, entre muchos otros, las obras de Verena Martínez-Alier, Marriage, class and colour in nineteenthcentury Cuba. A study of racial attitudes and sexual values in a slave society, Cambridge, Cambridge University Press, 1974; Asunción Lavrín (coord.), Sexualidad y matrimonio en la América Hispánica. Siglos XVI -XVIII, México, Grijalbo, 1991; Patricia Seed, Amar, honrar y obedecer en el México colonial. Conflictos en torno a la elección matrimonial, 1574-1821, México, Patria (Alianza), 1991; Ramón Gutiérrez, Cuando Jesús llegó, las madres del maíz se fueron. Matrimonio, sexualidad y poder en Nuevo México, 1500-1846, México, F.C.E., 1993; Pablo Rodríguez, Seducción, amancebamiento y abandono en la Colonia, Bogotá, LEALON, 1991; Pablo Rodríguez, En busca de lo cotidiano. Honor, sexo, fiesta y sociedad s. XVII - XIX, Bogotá, Universidad Nacional de Colombia, 2002; Ann Twinam, "Honor, sexualidad e ilegitimidad en la Hispanoamérica colonial", en Asunción Lavrín, (coord.), Sexualidad y matrimonio en la América hispánica: siglos XVI-XVIII, México DF., Grijalbo, 1991, 127-171. En tanto, el honor femenino en Chile, a partir del análisis de los juicios por incumplimiento de esponsales, ha sido trabajado en Consuelo Figueroa, "El honor femenino. Ideario colectivo y práctica cotidiana", en Diana Veneros (ed.), Perfiles revelados. Historias de mujeres en Chile, siglos XVIII-XIX, Santiago, Editorial Universitaria, 63-89, 1997.

22 Frédérique Langue ha propuesto esta vía de acceso al pasado colonial americano, en base a los parámetros de la "nueva historia social" europea de los '90. Véase su trabajo "Les identités fractales", op. cit., 24. Para un análisis crítico de los aportes y debilidades de la obra dirigida por Bernard Lepetit, que cristaliza las inquietudes de esta "nueva historia social", véase la reseña de Abel Ignacio López, "La historiografía francesa de los años noventa. Bernard Lepetit (director). Les formes de l'experience. Une autre histoire sociale. Paris, Albin Michel, 1995", en Anuario Colombiano de Historia Social y de la Cultura, Vol. 26, 1999, 373-386. La preocupación por el estudio de las prácticas sociales en el mundo colonial americano ha intentado replantear, por ejemplo, la historia de las instituciones, poniendo el acento en los actores sociales y en la acomodación de las normativas generales a las peculiaridades locales. Para el ámbito jurídico, véase Juan Carlos Garavaglia y Jean-Frédéric Schaub, Lois, Justice, Coutume. Amérique et Europe latines (16e-19e siècle), Paris, Éditions de L'Ècole del Hautes Études en Sciences Sociales, 2005.

23 Véase nota 13. 
judicial, estaremos perpetuando la mirada que una historiografía tradicional ha dado respecto del honor como ideal vinculado exclusivamente al ámbito de la élite, de cuya representación matriz podrían eventualmente emanar "derivaciones" hacia los otros grupos sociales. El estar abiertos a la posibilidad que tales sujetos efectivamente hayan participado de una representación particular de honor, vivido cotidianamente sus prácticas y actuado en su defensa cuando este era agredido, implica invertir las miradas y proponer nuevas categorías analíticas. Tales herramientas pueden venir de dos propuestas complementarias en algunos aspectos, ya sea a través de la perspectiva antropológica o de la historiográfica esbozada por Langue que habla de las "identidades en espejo". Ellas nos permitirán comprender las formas en las que élites, españoles pobres, artesanos o castas, por nombrar solo algunos de los actores sociales coloniales, construyeron representaciones y prácticas de honor según sus necesidades coyunturales e identitarias.

Al concebir el honor como uno de los supremos valores temporales de las sociedades y, por tanto, como un criterio susceptible de encontrarse en cualquier lugar y grupo -sea en las comunidades beduinas de Egipto, en las villas chipriotas, dentro de los grupos superiores o en los estratos populares-, la interpretación antropológica ha planteado esta noción como una de las formas de imposición de tipos socializados y pautas de comportamiento en las sociedades humanas ${ }^{24}$. Los aportes de la llamada "corriente de antropología social de Oxford", realizados desde mediados de los años 60 , revitalizaron los estudios sobre el honor mediterráneo, abriendo nuevas propuestas interpretativas que impulsaron decenas de publicaciones, rebasando pronto las fronteras de ese grupo. Así es como Peristiany, uno de los mayores representantes de dicha línea de investigación, ha señalado que "en la medida en que todas las sociedades evalúan la conducta refiriéndola a patrones ideales de acción, todas las sociedades poseen sus propias formas de honor y vergüenza ${ }^{25}$ ". Con ello, se cuestionaban las reivindicaciones etnocéntricas de un honor entendido como parte del "carácter" de una nación. Asimismo, la interpretación antropológica obligaba a pensar en un honor que no solo era característico de una estructura social estamental -en la que sus prerrogativas se circunscribían exclusivamente en las élites- ${ }^{26}$, sino que planteaba bases claras y precisas de un honor popular, con nudos temáticos estructurales, actitudes específicas, definicio-

24 Las líneas de análisis del honor mediterráneo abiertas por la interpretación antropológica, han abarcado aspectos tales como la posición social, el parentesco espiritual o compadrazgo, la familia, la hospitalidad y la sexualidad. Algunas de estas obras son: J. G. Peristiany (ed.), El concepto de honor, op.cit.; Julian Pitt-Rivers, Antropología del honor o política de los sexos. Ensayos de antropología mediterránea, Barcelona, Crítica,1979; Julian Pitt-Rivers y J. G. Peristiany (eds.), Honor y gracia, Alianza, Madrid, 1993; J. K. Campbell, Honnour, Family and Patronage: A Study of Institutions and Moral Values in a Greek Mountain Community, Oxford, Oxford University Press, 1964; J. Davis, People of the Mediterranean. An essay in comparative social anthropology, Londres, Routhledge and Kegan Paul, 1977.

25 J. G. Peristiany, El concepto de honor, op. cit. 12.

26 Para esta perspectiva véase José Antonio Maravall, Poder, honor y élites en el siglo XVII, Madrid, Siglo XXI, 1984. La sociología de Weber, a su vez, refrenda la conexión entre honor y "situación estamental". Max Weber, Economía y sociedad. Esbozo de sociología comprensiva, Santafé de Bogotá, F.C.E., 1997, 687-691. 
nes de género, gradaciones del estatus o mecanismos de apelación a la violencia, que en su conjunto conformaban un universo cultural definido y, con frecuencia, sofisticado $^{27}$.

Si desde el punto de vista antropológico, podemos constatar la universalidad cultural y la naturaleza polifacética del honor, como investigadores de lo particular y lo diacrónico, debemos develar las formas en que este código ha sido operado, resignificado o impugnado en los diversos contextos históricos que le han dado vida. Para el siglo XVIII chileno, ha sido habitual caer en una polaridad simplificadora entre una "alta" cultura y otra de raigambre "popular", que oculta tanto la diversidad de las formas como la existencia de mentalidades híbridas que puedan haber actuado como mediadores culturales ${ }^{28}$. Al pensar en términos de complementarios -en dinámicas "de espejos"- antes que de oposiciones observaremos a América colonial como un espacio privilegiado para los sincretismos, así como para la difusión de modelos culturales ${ }^{29}$.

\section{EL ESCENARIO Y LOS ACTORES: MICROSOCIEDADES MASCULINAS Y HONOR EN EL SANTIAGO DEL SIGLO XVIII}

La ciudad de Santiago, a lo largo del siglo XVIII, fue un polo de atracción de población del exterior e interior de la Capitanía General de Chile, que acudía a su emplazamiento en busca de mejores horizontes ${ }^{30}$. Mujeres y hombres de diversas naciones, oficios y calidades -o identidades definidas según el

27 Al respecto, los antropólogos han destacado la naturaleza polifacética del honor "y el hecho de que los diferentes grupos sociales valoran de forma distinta sus facetas". La representación del honor se articula en un marco diferente según cada lugar de la estructura social, y el valor específico atribuido a sus distintos aspectos puede explicarse por esto. Julian Pitt-Rivers, Antropología del honor, op. cit., 66 y 140 .

28 Hace ya treinta años, Carlo Ginzburg señalaba la necesidad de replantear la relación entre cultura popular y cultura de las élites, evitando caer en un paternalismo que llevara a la primera a ser mero reproductor de las ideas de la segunda. Si bien se ha tratado de soslayar este prejuicio, reemplazando el estudio de la cultura producida por los grupos populares al problema de la cultura impuesta a estos, la vía resolutiva más atractiva ha sido la de dar cuenta de la circularidad entre los niveles de cultura. Junto a ello, la noción de "cultura popular" ha resultado ampliamente problemática, por dar una falsa impresión de homogeneidad y expresar una división cultural reduccionista en dos niveles, olvidándose de la pluralidad de los pensamientos y comportamientos, así como de las modalidades específicas de apropiación de las significaciones culturales. Carlo Ginzburg, El queso y los gusanos. El cosmos según un molinero del siglo XVI, Barcelona, Península, 2001 ( $1^{\mathrm{a}}$ ed. 1976). Sobre el papel de los mediadores culturales, véase Berta Ares Queija y Serge Gruzinski (coord.), Entre dos mundos. Fronteras culturales y agentes mediadores, Sevilla, Publicaciones de la Escuela de Estudios HispanoAmericanos de Sevilla, 1997.

29 Frédérique Langue, "Les identités fractales", op.cit.; Serge Gruzinski, El pensamiento mestizo, Barcelona, Paidós, 2000.

30 Para analizar la influencia de Santiago dentro del sistema económico colonial veánse los estudios de Marcello Carmagnani, Los mecanimos de la vida económica en una sociedad colonial. Chile, 1680-1830, Santiago, DIBAM, 2001 y Romano Ruggiero, Una economía colonial: Chile siglo XVIII, Buenos Aires, Eudeba, 1965. Desde la perspectiva de la movilidad de los hombres en busca de oportunidades laborales y sociales veáse el interesante artículo, y vanguardista para la época, de Mario Góngora, "Vagabundaje y sociedad fronteriza en Chile siglos XVII-XIX)", en Estudios de historia de la ideas y de historia social, Valparaíso, Ediciones Universitarias de Valparaíso, 1980. 
origen/color- ${ }^{31}$, conformaban una muchedumbre de recién llegados. Muchos de los que venían del extranjero tenían conexiones en el país que les permitían contar con el apoyo de algún pariente o, al menos, de un coterráneo, asentándose transitoriamente en su residencia ${ }^{32}$. Otros, como peones y gañanes, encontraban refugio momentáneo en ranchos ubicados en la periferia, conformando una población flotante ocupada en oficios esporádicos y a veces confundida con vagabundos y malentretenidos ${ }^{33}$. Existían, asimismo, sujetos que contaban con algún grado de calificación laboral que les permitía obtener los recursos necesarios para arrendar cuartos estrechos al interior de la ciudad. Entre estos se contaban el peluquero Pedro Carrera y el médico Vicente Martres, ambos de nación francesa, quienes alquilaban habitaciones compartidas con compañeros en el sector de la Cañada baja, cerca de la Calle de los Baratillos ${ }^{34}$. El vínculo entre ellos, nosotros y el problema que nos convoca se materializa en un sustancioso proceso judicial seguido contra Carrera por el homicidio de su paisano y compañero de diversiones, Vicente Martres, ocurrido durante un duelo de espadas $^{35}$. Un suceso que nos permite conocer retazos de vidas masculinas obsesionadas por el honor y reconstruir en toda su riqueza las normas, jerarquías y parámetros conductuales de una microsociedad de franceses conformada en suelo chileno a mediados del siglo XVIII.

La relación que unía a Carrera y Martres era fuerte, estable y no dependía de su lugar de residencia ni del oficio practicado. Es más, este lazo podía ser transversal socialmente, uniendo en fidelidad y camaradería a sujetos de variados niveles sociales y económicos. Se trataba, siguiendo la terminología de la época, del paisanaje o relación de cercanía surgida a partir del reconocimiento del mismo lugar

31 McCaa, Robert, "Calidad, Class, and Marriage in Colonial Mexico: The Case of Parral, 1788-1790", HAHR, 64 (3), 1984, 477-501; Roland Anrup y María Eugenia Chaves, "La «plebe» en una sociedad de «todos los colores». La construcción e un imaginario social y político en la colonia tardía en Cartagena y Guayaquil”, Caravelle. Cahiers du monde hispanique et luso-bresilien, $\mathrm{N}^{\circ} 84$, 2005, 93-126.

32 Nuestras fuentes dan cuenta, al igual que la historiografía, de las redes que los vascos tejieron desde la Península con sus amigos y parientes en Chile, paso esencial en su rápida inserción social y promisoria bonanza económica. Véase, por ejemplo, Archivo Nacional Fondo Real Audiencia (en adelante A.N.R.A.) Vol. 3205, Pieza 1, 35 Fjs., Santiago, 1794. Don Benito Aspeitía Yañez solicita permiso para contraer matrimonio con doña Constanza Ferrer. En este expediente se puede observar la relación de amistad entre los padres de Aspeitía y don Manuel de Salas, quien sentía la obligación moral de actuar como padre del vasco recién llegado aconsejándole sobre sus planes matrimoniales. Ver también, Trinidad Zaldívar, María José Vial y Francisca Rengifo, Los vascos en Chile. 1680-1820, Santiago, Los Andes, 1998, 36-40.

33 Sobre la movilidad espacial de los peones, véanse los trabajos de Gabriel Salazar, Labradores, peones y proletarios. Formación y crisis de la sociedad popular chilena del siglo XIX, Santiago, Lom Ediciones, 2000; "Ser niño huacho en la Historia de Chile (Siglo XIX)", Proposiciones. Chile, Historia y Bajo Pueblo, $\mathrm{N}^{\circ}$ 19, Santiago, 1990, 55-83. La relación entre vagancia y los peones-gañanes ha sido estudiada por Alejandra Araya en Ociosos, vagabundos y malentretenidos en Chile colonial, Santiago, Dibam-Lom Ediciones, 1999, 67-80.

34 Armando de Ramón, Santiago de Chile (1541-1990). Historia de una sociedad urbana, Santiago, Editorial Sudamericana, 2000; "Santiago de Chile: 1650-1700", en Historia, N ${ }^{\circ} 12$, Instituto de Historia, Pontificia Universidad Católica de Chile, 1974-1975, 93-104.

35 A.N.R.A. Vol. 2537, Pza. 3, 70 Fjs. y A.N.R.A. Vol. 3224, Pza. 10, 9 Fjs. Contra Pedro Carrera por homicidio de Vicente Maestres, Santiago, 1752. 
origen por parte de los inmigrantes ${ }^{36}$. La tendencia de los extranjeros de buscar apoyo en sus coterráneos se veía reforzada por un contexto sociocultural preocupado por definir las identidades y construir las alteridades de los individuos según el origen. Los gestos taxonómicos de las sociedades coloniales que clasificaron y definieron moralmente a los sujetos según la pureza/impureza del nacimiento, fomentaron asimismo la construcción de identidades y estereotipos según el lugar de procedencia $^{37}$. Así, se fue conformando una geografía del nacimiento que definía caracteres y modos de conducta, especialmente visible respecto de los inmigrantes hispanos, pero que igualmente debió haber operado para los franceses en Chile ${ }^{38}$.

Los franceses que encontramos dentro del proceso judicial mencionado generaron férreos lazos de pertenencia entre sí, construyendo una microsociedad con jerarquías y paridades, normas y transgresiones, ámbitos de interacción y de confrontación. Peluqueros, médicos, bodegoneros, toneleros, pequeños comerciantes -o "mercachifles" como se los denomina en la documentación- estaban en permanente contacto, reuniéndose en los mismos espacios de sociabilidad. Bodegones y canchas de bolas de la ciudad de Santiago fueron el escenario de sus encuentros y la Cañada prestó su paraje para el duelo con el que dos paisanos procuraron vengar su honra la noche del diez de abril de 1752. Aquellos franceses que vivieron de sus oficios y compartieron cuartos con compatriotas para poder pagar la renta, nos acercan a las formas de vida de los inmigrantes que se insertaron en lo que podríamos llamar la "capa media" de la sociedad chilena del siglo XVIII. Relacionados con españoles pobres, artesanos y pequeños comerciantes, sus trayectorias personales expresan las dinámicas de conexión y distanciamiento que marcaron las for-

36 El Diccionario de Autoridades, deriva la voz "paisanaje", de "paisano", entendiendo que esta última hace referencia a "el que es de un mismo País, Provincia o Lugar que otro u otros. Es formado del nombre País". Real Academia, Diccionario de la lengua castellana, en que se explica el verdadero sentido de las voces, su naturaleza y calidad, con las phrases o modos de hablar, los proverbios o refranes, y otras cosas convenientes al uso de la lengua, Imprenta de la Real Academia Española por los herederos de Francisco del Hierro, Madrid, tomo V, 1737, 80.

37 La historiografía se ha referido ampliamente a la problemática de las identidades étnicas, en particular a la relación entre las categorías derivadas del mestizaje como la "sociedad de las castas" y la estructura social del mundo colonial americano. En términos generales, podemos señalar que el impacto inicial de los planteamientos de Magnus Mörner, que establecían una equivalencia entre "raza" y jerarquías sociales han sido cuestionados desde diversos ángulos. Las críticas en torno a las nomenclaturas utilizadas, como "raza" o "etnia", no solo expresan problemas semánticos, sino que pretenden dar cuenta de la ambigüedad de las identidades culturales y de los inconvenientes de obviar la estrecha vinculación entre dichas categorías y los mecanismos de dominación empleados por los hispanos. Solo algunos ejemplos: Magnus Mörner, La mezcla de razas en la historia de América latina, Buenos Aires, Paidós, 1969; Berta Ares Queija, "Mestizos en hábito de indios", op. cit.; Roland Anrup y María Eugenia Chaves, "La «plebe»", op. cit.; Robert H. Jackson, "Race/Caste and the Creation and Meaning of Identity in Colonial Spanish America", Revista de Indias, Vol. LV, $\mathrm{N}^{\circ} 203$, 1995, 149-173; John K. Chance y William B. Taylor, "Estate and Class in a Colonial City: Oaxaca in 1792", Comparative Studies in Society and History, Vol. 19, No 4, 1977, 454-487; Carmen Bernand, "De lo étnico a lo popular: circulaciones, mezclas, rupturas", en Nuevo Mundo Mundos Nuevos, N 6 , 2006, http://nuevomundo.revues.org/document1318.html

38 Respecto a la construcción de identidades/alteridades a partir del lugar de nacimiento, hemos hecho referencia a los prejuicios existentes sobre los gallegos en el siglo XVIII chileno y a algunas de las animadversiones entre estos y los vascos en nuestro trabajo "Honores transversales, honores polisémicos", op. cit. 
mas interacción entre ellos y la población local. Sus preocupaciones estaban lejos de las temáticas que una parte de la historiografía ha abordado respecto de los franceses asentados en Chile colonial, tales como su participación en el contrabando de manufacturas de valor o su vinculación a la élite hispanocriolla a través de matrimonios ventajosos ${ }^{39}$. Ellas giraban, más bien, al igual que muchos otros sujetos que vivían de sus oficios, en torno al ejercicio de sus labores para obtener el sustento diario. Si interrumpían sus tareas para acudir a espacios de diversión, siempre lo hacían acompañados de códigos de conducta y modelos valóricos marcados por la impronta de un honor construido desde sus coordenadas identitarias. Fue justamente la deshonra sufrida por uno de ellos en un ambiente de entretención la que demandó satisfacción a través de un duelo, quebrando para siempre la historia de aquella comunidad.

Legítimamente podemos preguntarnos ¿qué hacían dos franceses batiéndose a duelo en suelo chileno en las medianías del siglo XVIII? Si, por una parte, desde una óptica centrada en la "alta cultura", dicho período ha sido pensado como el siglo de la Ilustración y de las luces, vector de transformaciones que supuestamente harían del honor un ideal periclitado, ¿por qué existían hombres dispuestos a arriesgar su vida por un ideal superfluo y clasista, desde la perspectiva iluminista $?^{40}$. ¿Cuáles eran las circunstancias que obligaban a derramar la sangre del agresor como único camino para restituir el honor vulnerado, soslayando las vías institucionales de solución de los conflictos, tales como la justicia - a través de la figura legal de las injurias - o la mediación de individuos destacados de la comunidad? Por último, si el duelo ha sido pensado durante largo tiempo como recurso exclusivo de la élite, ¿que hacían dos sujetos al margen de los círculos de poder, cuyos oficios tendrían un precario prestigio social, recorriendo cada una de las etapas preestablecidas de aquellos intercambios violentos ritualizados $?^{41}$.

39 Jean-Pierre Blancpain, Francia y los franceses en Chile (1700-1980), Santiago, Hachette, 1987; Aníbal Escobar V., Francia y la colonia francesa en Chile, Santiago, Imprenta y Litografía La Ilustración, 1920; Fernando Campos Harriet, Veleros franceses en el Mar del Sur (1700-1800), Santiago, Zig-Zag, 1964.

40 Existen, sin embargo, diversos estudios que rebaten la visión que el advenimiento de la burguesía haya disminuido la preocupación por el honor, especialmente durante el siglo XIX. Véase Sandra Gayol, "Honor Moderno: The significance of honor in fin-de-siécle Argentina", HAHR, 84 (3), 2004, 475-498; Sandra Gayol, Sociabilidad en Buenos Aires. Hombres, Honor y Cafés 1862-1910, Buenos Aires, Ediciones del Signo, 2000; Sarah Chambers, From Subjects to Citizens, op. cit.; Verena Martínez-Alier, Marriage, class and colour, op. cit.; Peter M. Beattie, "The House, the Street, and the Barracks: Reform and Honorable Masculine Social Space in Brazil, 1864-1945, HAHR, 76 (3), 1996, 439-473; Thomas W. Gallant, "Honor, Masculinity, and Ritual Knife Fighting in Nineteenth-Century Greece", HAHR, 105, (2), 2000, 359-382; Kenneth S. Greenberg, "The Nose, the Lie, and the Duel in the Antebellum South", The American Historical Review, Vol. 95, № 1, 1990, 57-74

41 Sobre el menosprecio social al ejercicio de los médicos en Chile colonial, véase Vicuña Mackenna, Médicos de antaño, Buenos Aires, Editorial Francisco de Aguirre, 1974, 106-117. A1 respecto, contamos con un interesante proceso judicial por injurias entablado por un médico luego que un hombre lo insultase rebajando su oficio. Tal como expresan sus palabras, el otro sujeto "con violento desprecio y desdoro de mi onor y profecion me ymproperó notoriamente tratandome de que solo hera yo un sangrador, y no Medico". En consecuencia, solicita que el agresor se desdiga públicamente para la "restauración de mi onor, y Profesión". Archivo Nacional, Fondo Criminal, Legajo 1, expediente 2, Foja 1, Dn Agustin Gastaldes contra Dn Francisco Pérez por injurias, 1802, Sta Rosa del Huasco. Agradecemos a Emma de Ramón la posibilidad de revisar esta documentación cuando estaba 
Tales preguntas marcan algunas de las líneas que desarrollaremos a lo largo de esta presentación. Ellas nos hablan de la diversidad de las formas culturales, la ambigüedad de las categorías del honor y el poder creativo de las prácticas sociales. Observaremos cómo el duelo -en cuanto uso social del honor- atentaba contra las reiteradas políticas de control de la población por parte de la corona y de las autoridades locales, preocupadas de monopolizar la violencia en los organismos administrativos, eliminando prácticas tales como la venganza privada ${ }^{42}$. De esta forma, el honor actuaba como catalizador de conductas transgresoras, dejando de ser instrumento de disciplinamiento social para convertirse en el mejor aliado y medio para legitimar una violencia que podía relacionarse con motivaciones más "nobles", al inscribirse dentro de la defensa de la dignidad personal ${ }^{43}$.

Finalmente, la historia del médico y el peluquero da cuenta de los ambiguos soportes que sustentaban el prestigio en la sociedad colonial chilena del siglo XVIII. En su reconocimiento no bastaba la mirada de la élite, sino que convocaba diferentes juicios de valor según los espacios en los que este se estructuraba. Así, si un médico podía ser menospreciado en los círculos aristocráticos que recordaban los oscuros orígenes de un oficio ligado a barberos y cirujanos, entre los trabajadores manuales e incluso entre pequeños comerciantes, ese mismo sujeto podía gozar de amplio crédito y respeto. En el caso de la microsociedad de franceses que existió en suelo chileno a mediados del siglo XVIII, observamos que el médico Vicente Martres recibía gestos de respeto y disfrutaba de privilegios que no se aplicaban al peluquero Pedro Carrera. Sin embargo, la complejidad de las redes del estatus es aún mayor, pues fue el honor del peluquero el que se vio vulnerado y demandó un duelo como gesto reparador. El que las quejas de Pedro Carrera fuesen

en proceso de catalogación. Gonzalo Vial ha estudiado algunos de los prejuicios relativos a determinados oficios a fines del período colonial. Gonzalo Vial, "Los prejuicios sociales en Chile, al terminar el siglo XVIII. (Notas para su estudio)", BAChH, 73, 1965, 14-29. Sin embargo, estimamos que la perspectiva del autor, centrada particularmente en los mecanismos de exclusión, debe matizarse incluyendo asimismo las estrategias de reconocimiento desplegadas por parte importante de los individuos marginados por uno u otro criterio. Estos aspectos fueron abordados por nosotros en la Tercera Sesión de "Cátedras y Tertulias": "En busca de honor en Chile colonial: re-significación, categorías raciales y masculinidad", Archivo Nacional Histórico, 29 de agosto de 2006.

42 Sobre las formas de "venganza privada" en España y sus dominios desde los siglos XVI al XVIII y las dificultades de la corona para eliminar esta práctica, véase Francisco Tomás y Valiente, El Derecho Penal de la Monarquía absoluta (Siglos XVI - XVII - XVIII), Madrid, Tecnos, 1969, 46-80. Las políticas de control social desplegadas bajo la égida del despotismo ilustrado exceden ampliamente los parámetros de esta investigación. Para un análisis general del caso chileno, véase Jacques A. Barbier, Reform and Politics in Bourbon Chile, 1755-1796, Ottawa, University of Ottawa, 1980. Una línea interesante de análisis se refiere a los esfuerzos de la élite ilustrada por "ordenar" las diversiones públicas bajo los parámetros civilización/barbarie. Juan Pedro Viqueira Albán, ¿Relajados o reprimidos? Diversiones públicas y vida social en la ciudad de México durante el Siglo de las Luces, México, F.C.E., 2005.

43 La concepción del honor como instrumento de disciplinamiento social ha sido una de las vertientes más trabajadas en las aproximaciones historiográficas del tema, especialmente dentro de las perspectivas de la historia de género. Sin embargo, estas interpretaciones soslayan la existencia de un manejo social del honor, capaz de convertir esta noción en elemento legitimante de transgresiones del orden y la moral oficial. Para un resumen y discusión de esta perspectiva, véase Steve Stern, The secret history of gender. Women, men, and power in late Colonial Mexico, Chapel Hill \& London, The University of North Carolina Press, 1995, 14-19. 
escuchadas por el médico, no solo implicaba que este accedía al desafío sino que asimismo reconocía la legitimidad del honor del primero. Ello nos lleva una vez más a tomar en cuenta el carácter transversal y polisémico de un honor que podía ser reivindicado tanto por oidores y alcaldes como por artesanos, bodegoneros o peluqueros.

\section{EL ITINERARIO DE LA DESHONRA: CONFLICTOS MASCULINOS QUE VULNERAN EL HONOR}

El recorrido de la deshonra de "Pedro el peluquero" se fue fraguando durante el almuerzo del día lunes diez de agosto de $1752^{44}$. Como siempre, el grupo de franceses se había reunido en el bodegón de Pedro Potier, ubicado en la parte baja de la Cañada. Ese lugar constituía el punto de encuentro del grupo, un núcleo de sociabilidad que los congregaba cotidianamente, reforzando el sentimiento de pertenencia a una nación extranjera. Una larga mesa reunía a los hombres, que comían y reían al calor de la bebida. Todos, salvo Pedro, participaban de la reunión masculina. Marginado y sentado junto a las mujeres en el estrado, entre otras cosas por su menospreciada labor de servir los platos en el lugar, Pedro observaba la diversión que hombres y mujeres tenían lanzándose pelotillas de pan y uvas de una mesa a otra. Su humillación se iba forjando segundo a segundo. ¿Por qué -pensaría el peluquero- si esa misma mañana había estado jugando a las bolas con el médico Vicente Martres, compartiendo bromas y signos de familiaridad, ahora su compañero se sentaba en la mesa de los hombres mientras él era degradado al espacio femenino ? $^{45}$

Los ámbitos de las sociabilidades masculinas eran cruzados por distintos códigos que, si en unas circunstancias -como los juegos- permitían la camaradería entre hombres de distinta estimación social, en otras -como la acción de sentarse a una mesa a comer- prescribían reglas de interacción más estrictas y regidas por los criterios de discriminación socioculturales imperantes. Como toda sociedad, por muy pequeña que fuese su escala, dentro de la comunidad de franceses que estamos analizando, convivían lógicas de inclusión y exclusión de sus integrantes. Los criterios de paridad, originados esencialmente por la conciencia de pertenencia a la misma nación, eran suplantados por gestos diferenciadores que definían jerarquías dentro del grupo. Ellos permitían que por la mañana Pedro el peluquero y Vicente Martres se divirtieran juntos realizando diversas "demostraciones de amistad" y que por la tarde se ubicaran en espacios desiguales dentro del mismo bodegón ${ }^{46}$.

44 Esa es la forma en la que los testigos del caso, amigos y conocidos de Pedro Carrera, se referían a él. En algunas ocasiones, también se lo denominaba "Pedro el francés peluquero". A.N.R.A. Vol. 2537, Pza. 3, Fjs. 152 vta, 161vta y 164, entre otras.

45 Sobre el juego de bolas y otras diversiones del período véanse los trabajos de Eugenio Pereira Salas, Juegos y alegrías coloniales en Chile, Santiago, Editorial Zig-Zag, 1947 y Oreste Plath, Origen y folclor de los juegos en Chile: ritos, mitos, tradiciones, Santiago, Grijalbo, 1998.

46 Declaración del dueño de la cancha de bolas, quien estuvo presente cuando el médico y el peluquero fueron al lugar a divertirse. A.N.R.A., Vol. 2537, Pza 3, Fj. 163. 
Del mismo modo que la solidaridad entre paisanos permitía a Pedro Potier prestarle al peluquero los hornos de su bodegón para preparar los cabellos con los que confeccionaba las pelucas, la percepción de las distancias intracomunitarias le obligaba a marginar al último de la reunión masculina.

El vínculo de amistad que existía entre el médico y el peluquero francés estaba regido por las leyes no escritas, pero igualmente compulsivas, de una masculinidad que señalaba "la forma aprobada de ser varón en una sociedad determinada" 47 . Si tenemos en cuenta que las preocupaciones fundamentales de la identidad masculina tradicional -el poder, la autonomía, la dominación y la virilidad- fueron vulneradas aquella tarde para Pedro Carrera, descubriremos la dimensión de su deshonra ${ }^{48}$. Una humillación que incluso se expresaba gráficamente en su feminización, en su marginación al espacio mujeril.

En el universo masculino del honor, dejar una ofensa sin reparación equivalía a cobardía, lo que develaba la vinculación estrecha entre honor y valor, por una parte, así como entre cobardía y deshonor, por otra. En el caso de la primera dupla, se trataba de atributos que dentro de la estructura patriarcal han estado asociados a la masculinidad. Desde la psicología, se ha reseñado la construcción de la subjetividad masculina tradicional sobre una serie de pilares, entre los que destacan los rasgos de dureza relacionados directamente con la violencia y el poder ${ }^{49}$. En este contexto, el hombre cargaba con el imperativo de defender externamente, con sangre si era necesario, tanto su honor particular como el de su familia, del cual era titular $^{50}$. El ejercicio de la violencia física masculina vinculada al honor, podía realizarse contra la mujer -entendiéndose en este caso como corrección de conductas que hayan perjudicado el honor del padre, esposo o hermano- ${ }^{51}$, o contra otro hombre luego de una agresión al honor masculino, causada ya sea por un golpe, un insulto, la generación de un rumor o la interacción sexual con alguna mujer dependiente del hombre vulnerado.

47 Irene Meler, "La masculinidad. Diversidad y similitudes entre los grupos humanos", en Mabel Burin e Irene Meler, Varones. Género y subjetividad masculina, Buenos Aires, Paidós, 2000, 76.

48 Para un análisis de la masculinidad, en el ámbito popular chileno del siglo XIX, véanse los trabajos de Marcos Fernández L., Prisión común, imaginario social e identidad. Chile, 1870-1920, Santiago, Andrés Bello, DIBAM, 2003; "Perfiles masculinos al interior de la cárcel rural: historias de reos y soldados en el penal de Rancagua durante el siglo XIX", Revista de Historia Social y de las Mentalidades, Santiago, No 3, 1999, 137-168; "Pobres, borrachos, violentos y libres: notas para la reconstrucción de identidades masculinas populares en el siglo XIX”, en José Olavarría y Rodrigo Parrini (eds.), Masculinidad/es. Identidad, sexualidad y familia, Santiago, FLACSO-UAHC, 2000, 47 58. El caso argentino ha sido trabajado por Sandra Gayol, quien vincula la masculinidad a un honor popular ligado a la sexualidad, la fuerza física y la reputación. Véase su libro Sociabilidad en Buenos Aires, op. cit. Cabe destacar la semejanza de dicha construcción de la masculinidad en el mundo tradicional, independientemente del espacio geográfico en que esta se articulase. Para observar tales cercanías, por ejemplo, en el ámbito inglés del siglo XVII, véase Elizabeth A. Foyster, Manhood in Early Modern England. Honour, Sex, and Marriage, London and New York, Longman, 1999.

49 Mabel Burin, "Construcción de la subjetividad masculina", en Mabel Burin e Irene Meler, Varones. Género, op. cit., 130.

50 Consuelo Figueroa, "El honor femenino", op. cit.

51 María Teresa Rojas, "Agresión de hombre, defensa de mujer: una aproximación a la violencia conyugal y la justicia en el mundo popular. Zona central de Chile 1760-1830", Revista de Historia Social y de las Mentalidades, $\mathrm{N}^{\circ}$ 3, 1999, 89-116. 
El camino más corto para conseguir honor era arrebatar el del otro ${ }^{52}$. Entre los trabajadores manuales, como artesanos, carniceros o peones, un hombre que fallaba en defenderse a sí mismo contra los ataques de sus pares era marginado de la comunidad masculina. Como ha planteado Lyman L. Johnson para el Buenos Aires del mismo período, el estímulo de este tipo de conductas, acarreaba necesariamente reacciones agresivas que fomentaban las disputas en las diversas instancias de las sociabilidades masculinas, tales como las pulperías, las carreras de caballos, las apuestas y juegos de naipes, "generando un círculo interminable de desafíos y respuestas" 53 . Una trampa en el juego, el saludo de una mujer o la negativa de otro vaso de alcohol, expresaban y hallaban su significado en las preocupaciones fundamentales de la identidad masculina: el poder, la autonomía, la dominación y la virilidad. Cuestionar la honestidad de un hombre, así como su coraje o potencia sexual, era cuestionar su lugar en la sociedad masculina.

En este caso, el objeto de la marginación había sido Pedro el peluquero. No sabemos cuántos proyectiles de pan le llegaron a este antes de pararse e ir a buscar unos cocos al jardín para lanzarlos con violencia a la mesa de los hombres. Pese a que un sujeto llamado don Bartolomé recibió en la cabeza los frutos que Pedro había arrojado, no dio mayor importancia al suceso y continuó comiendo. Esta acción, o más bien la inacción de parte de un individuo desafiado por otro, implicaba dos cosas. En primer lugar, que el hombre desafiado no consideraba relevante la ofensa recibida, puesto que al venir de un sujeto que no era su igual, esta no rebajaba su honor en lo más mínimo. Según Bourdieu, el desafío -como fuente de honor- "sólo vale si se dirige a un hombre (en oposición a una mujer) y a un hombre honorable, capaz de dar una respuesta" 54 . El reto a un igual en la competencia del honor, implicaba el reconocimiento de esa igualdad y, por tanto, la posibilidad de recuperar el honor perdido violentando el del contrario. En el contexto referido, la preeminencia del sujeto agredido no solo estaba significada por su inclusión en la mesa de los hombres, sino que también por el apelativo de "don" con el que era designado por sus comensales y por el propio Pedro. El uso del “don”, para el período estudiado, ya no estaba reservado a los descendientes de conquistadores o a las élites coloniales, sino que había sufrido un desplazamiento semántico que permitía adjudicársele -aunque muchas veces luego de fuertes disputas- a todos quienes reivindicasen

52 Lyman L. Johnson, "Dangerous Words, Provocative Gestures, and Violent Acts. The Disputed Hierarchies of Plebeian Life in Colonial Buenos Aires", en Lyman L. Johnson y Sonya Lipsett-Rivera, The faces of honor, op . cit., 133. Véase también, Julian Pitt-Rivers, Antropología del honor, op. cit., 20-24.

53 Lyman L. Johnson, "Dangerous Words", op. cit., 130.

54 Pierre Bourdieu, La dominación masculina, Barcelona, Anagrama, 2000, 67. Al respecto, PittRivers señala: "Cuando el honor se ve impugnado, se lo puede vindicar. Ahora bien, el poder para impugnar el honor de otro hombre depende también de la posición relativa de los contendientes. Se considera que un inferior no posee honor suficiente para agraviarse por la afrenta de un superior. Un superior puede pasar por alto la afrenta de un inferior, ya que su honor no se ve comprometido por ella, si bien puede decidir castigar un atrevimiento. Los contendientes en duelo deben reconocer la igualdad, ya que están en condiciones iguales en él. [...] Un hombre es responsable de su honor solo ante sus iguales en la sociedad, es decir, ante aquellos con quienes compite conceptualmente". Julian Pitt-Rivers, Antropología del honor, op. cit., 30. 
limpieza de sangre, o a quienes gozasen de algún tipo de prestigio intracomunitario, como se dio en este caso ${ }^{55}$.

En segundo lugar, la renuencia de don Bartolomé a reconocer el reto, significaba que la pública deshonra de Pedro se magnificaba y que debía actuar lo antes posible para repararla. El peluquero se acercó a don Bartolomé: su intención debía leerse como una provocación que dejara al otro sin más salida que los puños o las espadas. Lo conminó a hablar, burlándose de su silencio, y al no recibir atención, a modo de estrategia para lograr su reconocimiento como par de parte de los hombres presentes, los desafió a todos, señalándoles que "allí estava el para qualquiera de los de la mesa"56. Apelaba, de esta forma, a su hombría, reivindicando su coraje frente a aquellos con los que estaba obligado a convivir cotidianamente. Sería justamente su hombría -íntimamente vinculada a la fuerza física y a la potencia sexual- la cualidad que lo podría restituir nuevamente al espacio masculino.

\section{De las PAlabras a los GeStos: LA DiALÉCTICA DESAFÍO-RESPUESTA EN LOS INTERCAMBIOS VIOLENTOS MASCULINOS}

Seguidamente, Pedro le dijo a su rival que, entretanto, se tomara un trago de vino. Sabiendo que sus palabras no pasarían inadvertidas y que serían interpretadas por todos los presentes como una afrenta directa a la conducta de don Bartolomé, asociando su proceder a la imagen social del borracho, el peluquero buscaba lavar su honra con sangre. Poco importaba si el rival de Pedro tuviese o no la afición de beber en exceso. Lo relevante aquí era que se apelaba públicamente a una de las injurias más utilizadas en el imaginario colonial para desprestigiar al competidor ${ }^{57}$. Como hemos indicado en otro lugar, la publicidad de las ofensas estaba dada por la presencia de testigos, potenciales generadores del rumor que luego oscurecería la reputación del afrentado ${ }^{58}$. En un mundo de relaciones cara a cara, en que el honor era esencial para la credibilidad y la inserción social, la permanencia del vínculo

55 Sobre los desplazamientos del uso del don y las luchas entabladas por la legitimidad de su apropiación, véase Frédérique Langue, "Les identités fractales", op. cit.

56 A.N.R.A., Vol. 2537, Pza 3, Fj.162.

57 Sobre la persistencia del término "borracho", catalogado como injuria en el período colonial, véase María Eugenia Albornoz, Violencias, género y representaciones: La injuria de palabra en Santiago de Chile (1672-1822), tesis inédita de Magíster en Género y Cultura, Santiago, Universidad de Chile, 2003, 43 y 45. William B. Taylor propone denominar los insultos "palabras de lucha", dado su papel como evento previo al enfrentamiento físico. A su vez, distingue los tipos de insultos según las identidades étnicas de quienes los enuncian. Véase su trabajo, Drinking, Homicide, and Rebellion in Colonial Mexican Villages, Stanford, Stanford University Press, 1979, 73-83. Para un análisis entre los insultos -entendidos ampliamente como palabras y gestos- y el orden social colonial, véase Sonya Lipsett-Rivera, "Los insultos en la Nueva España en el siglo XVIII", en Pilar Gonzalbo Aizpuru (dir.), Historia de la vida cotidiana en México, Tomo III El Siglo XVIII: entre tradición y cambio, México, El Colegio de México, F. C. E., 2005, 473-500. Un balance historiográfico de la temática en el mundo colonial americano, junto a nuevas propuestas, puede hallarse en Cheryl English Martin, "Popular Speech and Social Order in Northern Mexico, 1650-1830", Comparative Studies in Society and History, Vol. 32, $\mathrm{N}^{\circ}$ 2, 1990, 305-324.

58 Verónica Undurraga, "El honor no es más que la buena opinión, op. cit. 
con el otro no solo conllevaba reconocimiento sino que también permitía la obtención del sustento diario ${ }^{59}$.

En aquellas circunstancias, la respuesta de don Bartolomé no podía esperar. Según un testigo de los sucesos:

"Dn Bartholo le respondió que no era el borracho para que le dijese aquello asiendo al mismo tiempo el ademan de poner su mano en el pecho del Peluquero, $\mathrm{Y}$ este entonses agarro un cuchillo de la messa; y lo enpuño y hiso demostración de querer tirar con el con cuia nobidad se mobieron los sircustantes y el declarante le quito el cuchillo de la mano que las mugeres lo agarraron y echaron para fuera"60.

La dialéctica desafío-respuesta, había llevado a la parte ofendida -que en esta etapa del desencuentro era asumida por don Bartolomé- a tomar la iniciativa, combinando dos sistemas de defensa. Verbalmente niega la injuria y gestualmente al poner "su mano en el pecho del peluquero", interpreta el papel de agresor. Don Bartolomé había entrado en el juego de satisfacción del honor de Pedro el peluquero, apelando al sistema simbólico-corporal del honor que distinguía las partes superiores de las inferiores del cuerpo, calificando de nobles a las primeras y de vulgares a las últimas ${ }^{61}$. Al realizar este gesto, transgredía aquello que Georg Simmel ha llamado la "esfera ideal" que rodea el cuerpo de todo individuo ${ }^{62}$. La violación de dicho perímetro sagrado ya sea por medio de un golpe, empujón, rasguño o tirón de pelo, por ejemplo, no solo dejaba huellas físicas tangibles y expuestas a las miradas de los demás. Junto a la presencia física, en cada uno de los actores sociales coexistía una presencia moral, imagen social del individuo para la colectividad. Era justamente esta presencia moral, que podríamos llamar "reputación", la que acusaba los mayores resentimientos ante las afrentas y cuya reparación equivalía a una reincorporación al cuerpo social ${ }^{63}$.

Dentro de todas las ofensas físicas previas al intercambio violento en sí mismo, el gesto de poner la mano en el pecho del rival, empujándolo o tomando su ropa,

59 Sobre las sociabilidades estrechas en el Chile tradicional, véase René Salinas, "Espacio doméstico, solidaridades y redes de sociabilidad aldeana en Chile tradicional, 1750-1880", Contribuciones Científicas y Tecnológicas, Santiago, $\mathrm{N}^{\circ} 118,1998,1-19$.

60 A.N.R.A., Vol. 2537, Pza 3, Fj. 162.

61 Marta Madero, Manos violentas, palabras vedadas: la injuria en Castilla y León, siglos XIII $X V$, Madrid, Taurus, 1992, 13 (nociones que corresponden al prólogo de Jacques Le Goff). Sobre los usos de las metáforas corporales como expresiones del orden social dentro del mundo colonial americano, véanse los trabajos de Alejandra Araya, "Aproximación hacia una historia del cuerpo. Los vínculos de dependencia personal en la sociedad colonial: gestos, actitudes y símbolos entre elites y subordinados", en Monografías de Cuadernos de Historia $N^{\circ}$ 1, op. cit., 81-91; "La pedagogía del cuerpo en la educación Novo-Hispánica", Estudios Coloniales II, op. cit., 115-157; "Sirvientes contra amos: Las heridas en lo íntimo propio", en Rafael Sagredo y Cristián Gazmuri (directores), Historia de la vida privada en Chile, Tomo I: El Chile tradicional. De la Conquista a 1840, Santiago, Taurus, 2005, 161-197.

62 The Sociology of Georg Simmel, translated, edited, and with an introduction by Kurt H. Wolff, The Free Press of Glencoe, Glencoe, 1950, 321.

63 Sobre la relación entre deshonor y marginación social en el Chile del ocaso del período colonial, véase nuestro trabajo "El honor no es más que la buena opinión, op. cit. 
era una de las más ultrajantes. Este acto no entrañaba la ambigüedad de la palmotada en la espalda, sino que constituía una invitación directa a la pelea ${ }^{64}$. Ello explica la violenta reacción de Pedro, quien empuña un cuchillo. Estaba dispuesto a utilizarlo en ese instante, al igual que muchos hombres solían hacer para salvar su honor comprometido por los insultos y agresiones recibidas en pulperías y bodegones ${ }^{65}$. En este caso, los testigos de la disputa lo impidieron y, lo que fue aún más humillante para Pedro el peluquero, las mujeres terminaron expulsándolo del lugar. Sin embargo, antes de recibir ese último gesto de ignominia, Pedro alcanzó a intercambiar algunas palabras con su compañero de juegos de aquella mañana. Vicente Martres, había señalado en medio del altercado, que el peluquero "se merecía que le diesen palos por sus desacatos", una forma de castigo especialmente infamante, reservada para los animales o los esclavos ${ }^{66}$. Pedro, a punto de ser desalojado por las mujeres y a solo minutos de perder cualquier posibilidad de vengar su honra, se paró frente a Vicente pidiendo ratificación de la ofensa. Luego de conseguirla profirió un provocador "nos beremos" 67.

El desafío estaba formulado. Sus motivos explícitos. Sus actores definidos. Solo una pequeña reflexión sobre este último punto: los futuros duelistas. Pedro el peluquero debía escoger su rival entre los hombres de aquella mesa. Elige a Vicente Martres, opción que puede entenderse a raíz de la camaradería vivida aquella mañana en la cancha de bolas. Esta implicaba su mutuo reconocimiento como paisanos, miembros de una comunidad masculina, cuestión que vendría a ser la base de la percepción recíproca de la ofensa. Más tarde, Pedro le confesaría a Joachim Joseph Telles -su compañero de oficio con quien también compartía el cuarto donde vivía- que luego de los incidentes se encontraba especialmente molesto con Martres por un insulto que este había proferido en su contra. Se trataba del término "picaronazo", adjetivo aumentativo de "pícaro", que según el Diccionario de Autoridades evocaba aquello que era "bajo, ruin, doloso, falto de honra y vergüenza" ${ }^{6}$. Dicha palabra, pronunciada en voz alta frente a todos los circunstantes, expresaba en realidad la opinión de los hombres sentados a la

64 La gama de interpretaciones construidas en torno a los contactos físicos masculinos en espacios laborales y de recreo en el Buenos Aires del siglo XVIII, han sido reseñados en Lyman L. Johnson, "Dangerous Words", op. cit., 132 y 133.

65 Este problema lo abordamos en la ponencia titulada "Cuando las afrentas se lavaban con sangre: honor y violencia popular en Chile colonial", III Seminario historiadores de Chile: Mario Góngora. Vida, ideas e historiografía, Instituto de Historia, Pontificia Universidad Católica de Chile, Santiago de Chile, noviembre de 2006.

66 A.N.R.A., Vol. 2537, Pza 3, Fj. 164vta. Sobre las significaciones sociales de las penas corporales, véase Alejandra Araya, "El castigo físico: el cuerpo como representación de la persona, un capítulo en la historia de la occidentalización de América, siglos XVI-XVIII", Historia, No 39, Vol. 2, Santiago, 2006, 349-367. Desde la perspectiva legal, véase el minucioso trabajo de Patricia Zambrana Moral, "Rasgos generales de la evolución histórica de la tipología de las penas corporales", Revista de Estudios Histórico-Jurídicos, Escuela de Derecho, Pontificia Universidad Católica de Valparaíso, XXVII, 2005, 197-229. Para el ámbito mexicano, véase Gabriel Haslip-Viera, Crime and punishment in late colonial Mexico City, 1692-1810, Albuquerque, University of New Mexico Press, 1999, 101-131.

67 A.N.R.A., Vol. 2537, Pza 3, Fj. 164vta.

68 Real Academia Española, Diccionario de la lengua castellana, op. cit., Tomo V, 1737, voz: «pícaro», 257. 
mesa: Pedro el peluquero carecía de honor. Tal vez la práctica de un oficio privado de prestigio, sumado a su pobreza material que lo obligaba a trabajar como sirviente en el bodegón de Potier, lo relegaban a un espacio inferior "bajo", como señala la fuente- en la sociedad de franceses ${ }^{69}$. Según tales rangos, Pedro no debió ofenderse al ser relegado de la mesa de los hombres, que para estos efectos, pasaba a ser la mesa del honor. Desde esa óptica, el peluquero no habría sabido mantener su lugar, transgrediendo las jerarquías que sellaban el estatus dentro del grupo.

Nos encontramos, por tanto, ante la doble faceta del honor que mencionábamos al comenzar esta presentación. En cuanto espacio relacional, este construía lazos de comunicación que permitían la convivencia y normaban las formas de interacción. En tanto ámbito de confrontación, el honor era objeto de continuas disputas y desavenencias acerca de sus usos, atribuciones y componentes. Se trataba, en muchos casos, de luchas entre representaciones divergentes, relacionadas con las coordenadas identitarias particulares de cada uno de los sujetos coloniales. Para Pedro el peluquero, pese a la opinión de los demás, la hombría era esencial en la representación del honor. Ella le permitía relacionarse con el médico Vicente Martres, divirtiéndose en ambientes masculinos, para luego ofenderse ante la incursión sexual del compañero -ahora rival- con alguna mujer.

En efecto, existían conflictos pendientes entre las partes, derivados de las visitas que ambos realizaban a unas mujeres llamadas "las Valdivianas" que ubicaron temporalmente su "casa de citas" en la morada vecina al bodegón de Potier. El oficio practicado por ellas no impidió que la hombría de Pedro fuese vulnerada cuando Vicente Martres comenzó a frecuentar a la mujer con la cual el primero solía intimar ${ }^{70}$. Ello no solo corrobora la estrecha relación entre hombría y potencia sexual, ampliamente estudiada desde el punto de vista histórico y antropológico $^{71}$, sino que extiende sus implicancias independientemente de la naturaleza del vínculo existente entre mujeres y hombres. Esto, puesto que la literatura ha tendido a asociar el honor masculino a la capacidad de control de la sexualidad de las mujeres dependientes -ligadas al hombre a través de la ley o la sangre- hayan sido esposas, hijas o hermanas. Sin embargo, para el Chile del siglo XVIII hemos observado que este podía ser vulnerado, a su vez, por el comportamiento de aquellas mujeres unidas en "amistad ilícita" al hombre, lo cual ciertamente expresaba la vigencia de universos culturales que validaban las

69 La carencia material en la que vivía Pedro Carrera puede constatarse del escuálido inventario de sus bienes, realizado por la justicia luego de la sentencia condenatoria. Dicho procedimiento era habitualmente realizado con el fin de cubrir los costes del proceso judicial. A.N.R.A. Vol. 3224, Pza. 10 , Fjs. 101 y $101 \mathrm{vta}$.

70 La esposa de Potier señaló que, durante el almuerzo, Pedro el peluquero se refirió a Vicente Martres como "ese perro [que] me tiene partido el corazon porque entra a una casa de unas mugeres a quienes yo bisito”. A.N.R.A., Vol. 2537, Pza. 3, Fj. 165.

71 Julian Pitt-Rivers, Antropología del honor, op. cit.; J. G. Peristiany (ed.), El concepto de honor, op. cit.; J. K. Campbell, Honnour, Family and Patronage; Pierre Bourdieu, La dominación masculina; Robert Nye A., Masculinity and male codes of honor in modern France, New York, Oxford University Press, 1993; Elizabeth A. Foyster, Manhood in Early Modern England. 
uniones de hecho ${ }^{72}$. Ahora bien, el caso que nos ocupa va más allá de estas consideraciones, mostrando la versatilidad de los usos sociales que hacían descansar el honor masculino en una potencia sexual incuestionable. Desconocemos si existió algún tipo de vínculo formal entre el peluquero y aquella mujer o si los otros hombres estaban al tanto de la afición de Pedro por ella. Ante nuestras conjeturas, escuchamos el silencio de un registro judicial que no abordó sistemáticamente esta línea de investigación, al decidir buscar las motivaciones del duelo en los incidentes ocurridos esa misma tarde en el bodegón de Potier ${ }^{73}$. Por el momento, solo se nos ha permitido ser espectadores de la ambigüedad de las redes de significaciones que se tejían sobre los diversos tipos de vínculos que podían unir a un hombre y a una mujer en el pasado colonial.

\section{Duelo De ESPADAS O EL PODER RESTAURADOR DE LA SANGRE}

Luego de proferir aquel amenazante "nos veremos", Pedro tuvo toda la tarde para preparar su venganza. Se reunió en su cuarto con unos vecinos, quienes le prestaron una espada larga adecuada para el enfrentamiento ${ }^{74}$. Salió de la habitación que arrendaba con un compañero de oficio, llevando el arma y su capote para ocultar su identidad mientras esperaba que Vicente, luego de cenar, saliera del mismo bodegón donde solo horas antes habían ocurrido los incidentes. El peluquero se acercó al médico señalándole, frente a otro hombre, que necesitaba que visitase a una enferma. Ante la respuesta afirmativa de Vicente Martres, Pedro Carrera aparta unos metros a su rival y le señala que el enfermo es él mismo por las palabras con las que lo había agraviado aquella tarde. Proponiendo el deshonor como enfermedad que margina del cuerpo social y planteando el duelo como recuperación y reinserción, Pedro se trenza

72 Se trata de uno de los aspectos que estamos trabajando en el marco de nuestra tesis doctoral y al que hicimos referencia en la ponencia ya citada "Cuando las afrentas se lavaban con sangre". Sobre la aceptación comunitaria de los vínculos de convivencia entre hombres y mujeres, sin que mediase el sacramento del matrimonio, véanse los trabajos de Eduardo Cavieres y René Salinas, particularmente su obra Amor, sexo y matrimonio en Chile tradicional, Valparaíso, Universidad Católica de Valparaíso, 1991; René Salinas, "La transgresión delictiva de la moral matrimonial y sexual y su represión en Chile tradicional. 1700-1870", Contribuciones Científicas y Tecnológicas, Santiago, $\mathrm{N}^{\circ} 114$, noviembre 1996, 1-23.

73 Para la fecha en que se conoció ese dato dentro del proceso judicial, las mujeres mencionadas ya se habían ido del lugar. La ambivalencia de la posición de los hombres frente a ellas se expresa en varias de las declaraciones de los testigos del caso. Algunos admitieron frecuentarlas, pero a su vez, decían sentirse incómodos por su presencia en el barrio, seguramente una posición asumida ante los representantes de la justicia. A.N.R.A., Vol. 2537, Pza. 3, Fj. 165.

74 Un testigo describe el arma como "espada larga de estas de marca, de guarnición de escudilla mui bien pabonada". El dueño de la espada era “don Ignacio Corona”, mercader que tenía su tienda ubicada al lado del cuarto de Pedro Carrera y su compañero. Corona señala que Carrera debió ir a buscar el arma a la habitación de Joseph Astorga, "mercader de aquella vecindad", a quien se la había prestado la noche anterior. Es más, en el momento del interrogatorio, Corona no tenía la espada en su poder, pues la había prestado al mercader Dn. Juan de Santiago. El expediente no responde la interrogante de si Astorga o Santiago habrían utilizado la espada en un duelo, pero de todas formas, la imagen de aquella arma yendo de mano en mano de los hombres del lugar es sumamente sugerente. A.N.R.A., Vol. 2537, Pza. 3, Fjs. 169-170vta. 
con el médico en una discusión que solo podía terminar en un enfrentamiento violento. Vicente se dirigió raudamente a su casa a buscar su espada, para luego volver al lugar fijado, al sur de la Cañada. La mañana siguiente, cuando se abre el auto de procesamiento por el homicidio del médico Vicente Martres, testigos señalan que la noche anterior, durante largo rato, oyeron ruido de espadas y luego una voz que exclamaba: "Pedro, estoy herido"75.

Los amigos y rivales se habían encontrado por la noche para lavar su honra con sangre. Las circunstancias que habían mancillado el honor de Pedro el peluquero y el escenario en el que las afrentas se habían desarrollado, lo obligaban a reivindicar abiertamente los atributos de una masculinidad centrada en la dominación, la fuerza física y la potencia sexual. Si su hombría había sido vulnerada tan flagrantemente aquella tarde, debía recobrarla tomando la del otro hombre. Ello explica que haya elegido la violencia como medio para reparar su honor, soslayando los mecanismos institucionales de solución de los conflictos interpersonales. En ocasiones, la venganza del honor dañado solo se conseguía con derramamiento de sangre ${ }^{76}$. El honor, inscrito en la "esfera ideal" 77 y sagrada de la persona, precisaba de expiaciones inmersas en ese mismo campo, reparándose a través de prácticas inscritas en ámbitos sacralizados y ritualizados por el hombre. El papel de la sangre humana como sustancia capaz de expiar los daños, encuentra su máxima expresión en la figura de un Cristo latigado, crucificado y sangrante de la cosmovisión cristiana. El duelo como expiación, como reparación del honor dañado, encuentra en la sangre su bálsamo restaurador. Sus reglas establecían que el evento que marcaba el fin del enfrentamiento era la primera herida con derramamiento de sangre en el cuerpo de uno de los duelistas ${ }^{78}$.

Las normas que regían su desarrollo le otorgaban el aspecto de un ritual, preocupado de formas que desplazaban el acento de la substancia y la función ${ }^{79}$. En este sentido podríamos hablar de una estilización de la violencia, que procura disfrazar la realidad groseramente material del acto de luchar hombre a hombre, juntando los cuerpos, sudando, sangrando. La creación de universos simbólicos para sus etapas, armas, tiempos y participantes, han sido vistas por la historiografía como uno de los tantos esfuerzos desplegados por las élites para legitimar sus prácticas y distinguirlas de las de los otros grupos ${ }^{80}$. La diferencia operaría en este

75 A.N.R.A., Vol. 2537, Pza. 3, Fjs. 160, 163 y 168vta. Pedro Carrera fue condenado a muerte en la horca por homicidio.

76 "Es evidente que el duelo, tal como se lo entiende en la Europa clásica, nos sitúa en la confluencia de conceptos de distinto origen: venganza de la sangre y castigo del ultraje". Jean-Paul Roux, La sangre. Mitos, símbolos y realidades, Barcelona, Península, 1990, 185. Véase también Mentalites. Histoire des Cultures et des Sociétés, No 1: Affaires de Sang, Paris, Imago, 1988.

77 The Sociology of Georg Simmel, 321.

78 V. G. Kiernan, El Duelo en la Historia de Europa. Honor y privilegio de la aristocracia, Madrid, Alianza, 1992, 162.

79 Pierre Bourdieu, La distinción, 195-197.

80 La bibliografía referida a los duelos es amplia. Para el ámbito europeo, solo desde el punto de vista historiográfico, podemos citar: Claude Chauchaudis, La loi du duel: le code du point d'honneur dans l'Espagne des XVI et XVII siècles, Toulousse, Presses Universitaires du Mirail, 1997; Robert Nye A., Masculinity and male codes, V. G. Kiernan, El Duelo en la Historia, op. cit. Asimismo, tomando en cuenta exclusivamente la historiografía, para el espacio americano podemos mencionar: Sandra 
caso entre una violencia refinada y otra de raigambre popular, representada -según la perspectiva elitista- como caótica, irracional, informal, ajena a valores y a objetivos predefinidos. Tales consideraciones han venido siendo refutadas durante los últimos años, mostrando que relacionada a determinados valores sociales como el honor, la violencia popular podía ser entendida como un sistema de venganza privada, sujeta a normas y códigos particulares ${ }^{81}$. Reflexiones como estas, procedentes de disciplinas como la antropología, deben obligarnos a repensar las categorías y matizar los juicios respecto de las representaciones y prácticas del honor en el pasado colonial. Si la violencia popular podía estar relacionada a valores y códigos formales específicos, también debemos estar abiertos a la posibilidad que el duelo no fuese atributo exclusivo de la élite y que el honor tampoco fuese un código monolítico, reservado a los grupos privilegiados, sobre el cual existiese consenso comunitario.

\section{UN HONOR ESQUIVO}

El peluquero Pedro Carrera persiguió un honor esquivo, gozó de sus privilegios para luego perderlos en un juego social de competencias y solidaridades, de pendencias y camaraderías. Desde un universo masculino asentado en la fuerza física y la virilidad, debió lavar su honor con la sangre de un compañero y, finalmente, con la propia. Sabía que al salvar su honor arriesgaba perder la vida, como efectivamente sucedió la mañana del 4 de julio de 1752 cuando fue ahorcado por mandato de la Real Audiencia, por su confesada autoría del homicidio de Vicente Martres ${ }^{82}$.

Gayol, "Duelos, honores, leyes y derechos: Argentina, 1887-1923", en Anuario IEHS, Facultad de Ciencias Humanas, Universidad Nacional del Centro, Tandil-Argentina, No 14, 1999, 313-330; David S. Parker, "La ley penal y las "leyes caballerescas": hacia el duelo legal en el Uruguay, 1880-1920", en Anuario IEHS, Facultad de Ciencias Humanas, Universidad Nacional del Centro, Tandil-Argentina, $\mathrm{N}^{\circ}$ 14, 1999, 295-311; Pablo Piccato, "La política y la tecnología del honor: el duelo en México durante el porfiriato y la revolución”, en Anuario IEHS, Facultad de Ciencias Humanas, Universidad Nacional del Centro, Tandil-Argentina, N 14, 1999, 273-294; Nelly Porro Girardi, "La defensa de la honra a uso de Indias", Revista Chilena de Historia del Derecho, Santiago, Facultad de Derecho Universidad de Chile, $\mathrm{N}^{\circ} 12,1986,323-331$.

81 Se trata de una perspectiva que estamos desarrollando dentro de nuestra investigación sobre el honor en el siglo XVIII chileno y que presentamos en la ponencia ya citada "Cuando las afrentas se lavaban con sangre". Para la perspectiva antropológica, véase Pierre Bonte e Michael Izard (dir.), Diccionario de etnología y antropología, Madrid, Akal, 1996, 732-735; Joseph Ginat, Blood disputes among Bedouin and rural Arabs of Israel, Pittsburgh, Pennsylvania, University of Pittsburgh Press, 1987; Raymond Verdier (dir), La vengeance. Etudes d'ethnologie, d'histoire et de philosophie, Paris, Editions Cujas, 4 vols., 1980-1984. Desde el punto de vista historiográfico, véase Pieter Spierenburg (ed.), Men and Violence. Gender, Honor and Rituals in Modern Europe and America, Ohio, Ohio State University Press, 1998. Destacamos especialmente el sugerente trabajo de Thomas W. Gallant, "Honor, Masculinity, and Ritual Knife Fighting in Nineteenth-Century Greece", The American Historical Review, Vol. 105, No 2, 2000, 359-382.

82 La Real Audiencia revoca la pena de primera instancia que condenaba a Pedro Carrera al tormento, aplicándole "la pena ordinaria de muerte, la que le fuese dada, siendo sacado de la carzel, cavallero en vestia de albarda, con soga de esparto, en la garganta, y llevando con bos de pregonero que manifieste su delito, a la orca que estara puesta en la plaza mayor, y en ella sera hizado, y colgado, hasta que naturalmente muera, de donde ninguna persona sea osado, de quitar el cuerpo, sin expresa licencia de esta Real Audiencia”. A.N.R.A. Vol. 3224, Pza. 10, Fj. 98. 
Sin embargo, también conocía los costos de una deshonra que quebraría los lazos que lo unían a los demás miembros de aquella microsociedad de franceses asentada en suelo chileno a mediados del siglo XVIII. Solo si tenemos en cuenta que el honor y los criterios a él relacionados -como el buen nombre y la reputación-, más que adornos superfluos eran fundamentos de la confianza que permitía entablar relaciones comerciales y de camaradería, entenderemos la importancia vital que aquel valor tenía en las sociedades tradicionales.

La relevancia del honor en el juego social del siglo XVIII chileno, hacía de este un lenguaje común que vinculaba bajo sus códigos y nomenclaturas a parte importante de los sujetos coloniales, quienes apelaban a sus tratamientos y reivindicaban sus gestos. Sin embargo, las aspiraciones individuales de honor solo eran efectivas si lograban ser reconocidas socialmente y aquí es cuando comenzaban las discrepancias que hacían del honor un espacio de confrontación. Justamente en ello radica el núcleo dramático de la historia de Pedro Carrera y Vicente Martres: la ambigüedad de un honor que en unas circunstancias podía ser patrimonio de todos y en otras, lo era solo de algunos. 